\title{
Interaction between Glycogen Body Cell and Neuron: Examination in Co-culture System
}

\author{
Tomohiro IMAGAWA ${ }^{1)}$, Kyoko SHOGAKI ${ }^{1)}$ and Masato UEHARA ${ }^{1)}$ \\ ${ }^{1)}$ Department of Veterinary Anatomy, Faculty of Agriculture, Tottori University, Tottori 680-8553, Japan
}

(Received 1 May 2006/Accepted 15 June 2006)

\begin{abstract}
The glycogen body (GB) is in the dorsal area of the lumbosacral spinal cord in birds and is composed of uniform cells characterized by high glycogen storage. The glycogen of GB cells remains unchanged in vivo by the effects of a variety of hormones such as insulin, glucagon, adrenocorticotropic hormone and by physiological conditions such as starvation. In order to investigate the latent functionability of GB cells, we observed morphological changes of glycogen body cells in a co-culture system with cerebellar neurons by light and transmission electron microscopy. Cultured GB cells were labeled with 1,1'-dioctadecyl-3,3,3',3'-tetramethylindocarbocyanine perchlorate (DiI). The cultured neurons derived from cerebellum were co-cultured with the labeled GB cells. Under the co-culture with neurons, 2 types of GB cells were detected. One was conventional with numerous glycogen deposits in the cytoplasm and tended to make clusters. The other type of GB cells singly extended the processes attaching to the neuronal body and axons. In the axons in contact with GB cell processes, small vesicles appearing as synaptic vesicles were observed. These observations suggested that some GB cells can differentiate to an average astrocyte. The GB cells were assumed to involve the synapse formation or maturing as astrocytes in the CNS.
\end{abstract}

KEY WORDS: astrocyte, avian, CNS, co-culture, neuron.

The glycogen body (GB) is an ovoid gelatinous mass located in the lumbosacral region of the spinal cord in birds, and is composed of uniform GB cells [31]. Developmentally, the GB appears as a periodic acid Schiff (PAS)-positive cell cluster at about 7 to 8 days of incubation and increases in volume as elaborated large stores of glycogen after 15 days of incubation $[6,19]$. The PAS-positive cells, GB cells, arise from the neuroepithelium that comprises the ependyma and roof plate of the avian lumbosacral spinal cord [7]. In in vitro experiments, the GB cells contain glial fibrillary acidic protein in the cytoplasm $[16,18]$. Thus, it is recognized that the GB cells are derived from an astrocyte lineage.

According to the classical view, glial cells have been recognized as silent cells in the central nervous system (CNS), and their main roles are to support the physiology of associated neurons. That is, the astrocytes participate in numerous functions in addition to structural support, e.g., regulation of the ionic environment and clearing neurotransmitter released from synapse [4], responding to the metabolic demands of neurons [23], uptake of neurotransmitters, regulation of extracellular cation levels, and metabolic support of neurons [1]. Recently, astrocytes have been proposed to have the new function of modulating synapse formation and maturation $[13,28]$.

The mature GB is a very stable tissue. The glycogen content of GB is not altered by effects of a variety of hormones $[14,24]$ or by starvation $[6,11]$. Furthermore, GB shows normal development with high glycogen content under some experimental conditions, such as grafting to chorioallantoic membrane or tail bud removal $[6,8]$.

In our previous study, we confirmed that the GB cells were of astrocyte lineage, and that glycogen contents are affected by a neurotransmitter, noradrenalin, in vitro [18]. However, there is little information about the interaction between the GB cells and neuronal elements, because neurons are not observed in the mature GB. In the present study, we seek to elucidate a possibly masked function of GB cells by making them interact with neurons, which may be a strong stimulation for the GB cells. We investigated the morphological changes of GB in co-culture with cerebellar neurons.

\section{MATERIALS AND METHODS}

GB cell culture: GBs were prepared from 5 White Leghorn chick embryos at 15 days' incubation. The cells were cultured by the method of Lee et al. [18]. In brief, the GB was dissected and dissociated mechanically and chemically with $0.25 \%$ trypsin (Invitrogen Ltd., U.S.A.). The isolated cells were incubated in Dulbecco's modified Eagle's medium (DMEM)-supplemented with 10\% FCS (Invitrogen Ltd., U.S.A.), $50 \mathrm{U}$ penicillin and $50 \mu \mathrm{g}$ streptomycin $/ \mathrm{m} l$ in $35-\mathrm{mm}$ Petri dishes at $37^{\circ} \mathrm{C}$ in a $5 \% \mathrm{CO}_{2}$ atmosphere with $95 \%$ humidity. The culture medium was renewed twice a week.

DiI (Molecular Probe, U.S.A.) labeling: DiI, lipophilic carbocyanine dye, has been developed to provide labeling in long-term cell tracing and shows very low cell toxicity. Cultured GB cells after 3, 6 and 9 days were incubated with $40 \mu \mathrm{g} / \mathrm{m} l$ DiI in DMEM for $1 \mathrm{~min}$ at $37^{\circ} \mathrm{C}$. The cultures were washed twice with DMEM, and suspended by $0.25 \%$ trypsin. To count labeled cells, a portion of the cells was fixed with $10 \%$ formalin, and observed under fluorescent microcopy.

Neuron culture: Cultures were as described by Furuya et 


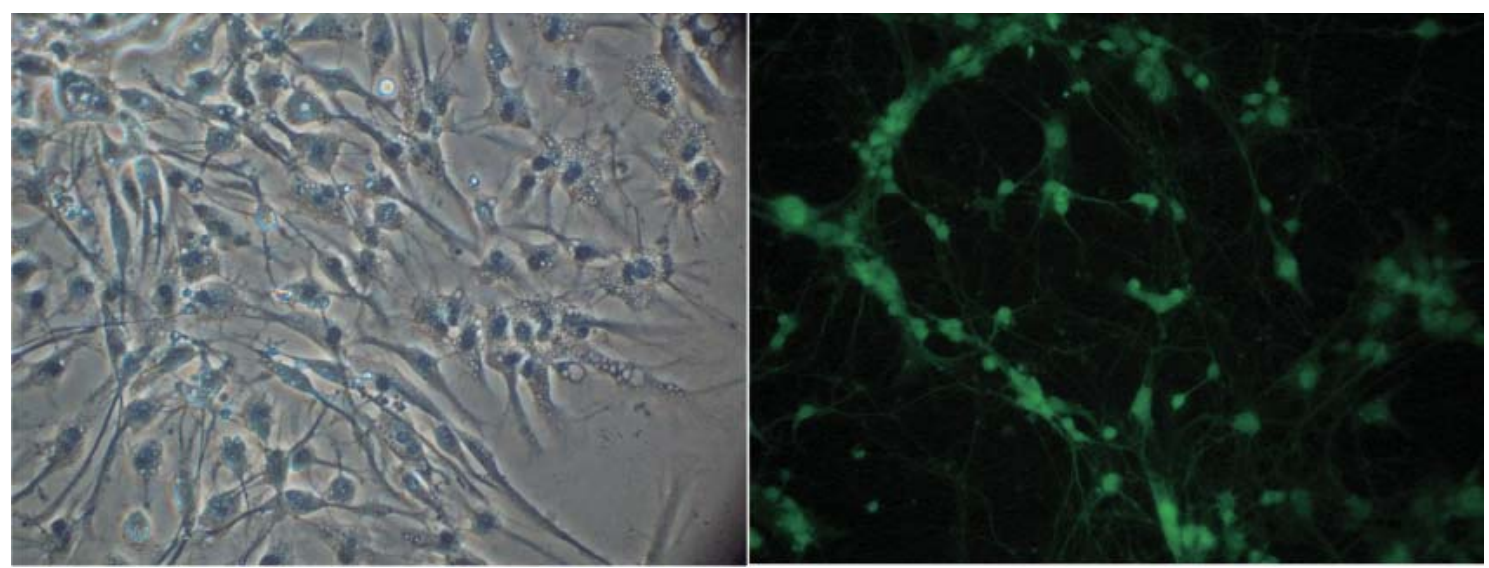

Fig. 1. (a) Phase contrast micrograph of cultured cerebellar cells at 5 days. Many cells possess round nucleus and a few long processes. (b) Fluorescent micrograph of anti-tubulin immunostained cerebellar cells cultured for 3 days. Most cultured cells are tubulin positive and make meshwork by their processes. Bars: $20 \mu \mathrm{m}$.
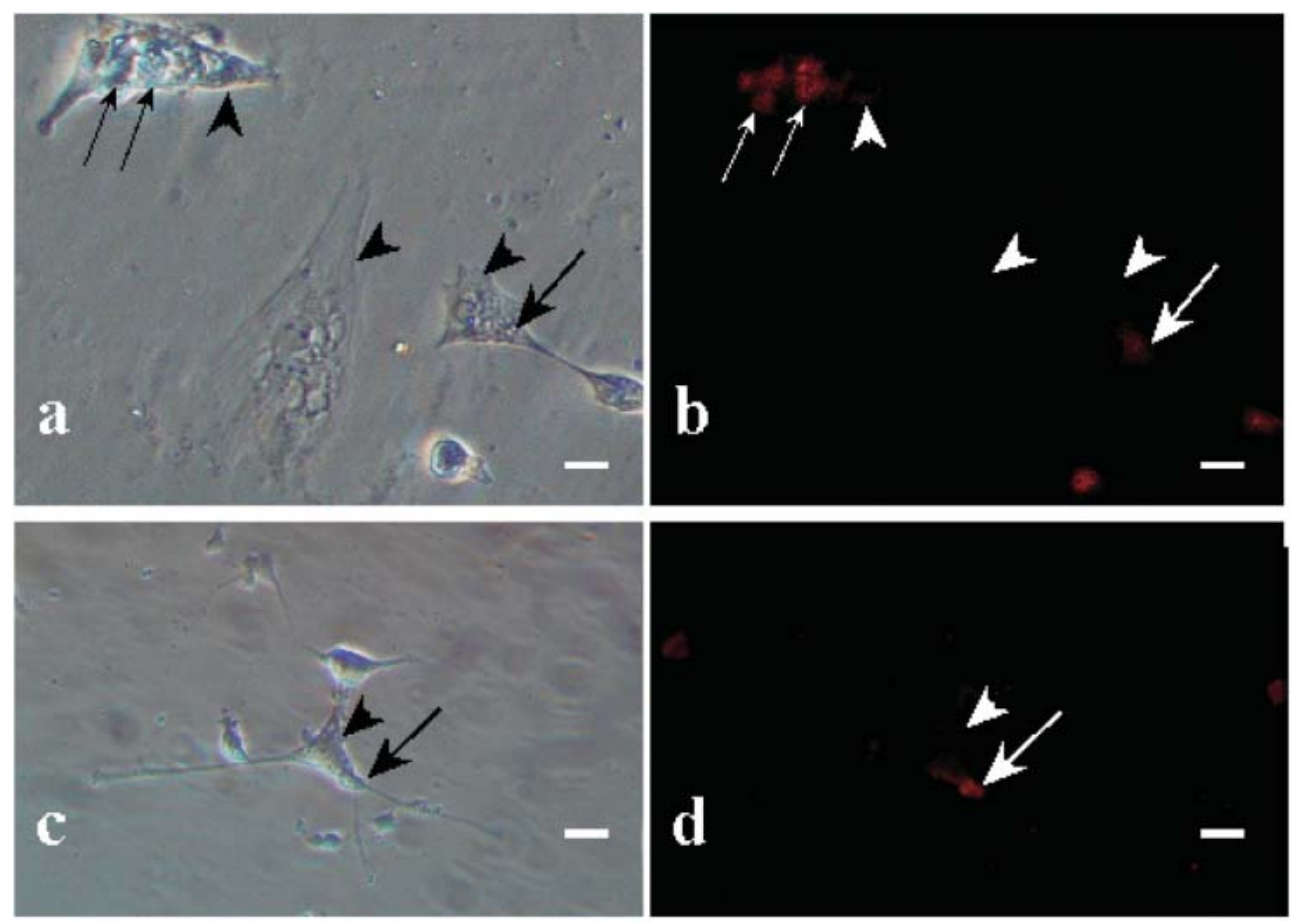

Fig. 2. Photographs of co-cultures under phase contrast microscopy (a and c) and fluorescent micrographs of the same area as left column respectively ( $b$ and d). Arrowheads indicate neurons. Arrows show GB cells with red fluorescent of DiI in right column. GB cells make a small cluster around a neuron (small arrows in a and b). Some GB cells independently attached to the neuron and extended processes (large arrows). Bars: $10 \mu \mathrm{m}$.

al. [9] with some modifications. The cerebella were removed from 3 White Leghorn chick embryos at 15 days' incubation, and transferred to Hanks' balanced salt solution (HBSS). The meninges were completely removed under dissection microscope. Small pieces of the cerebella were washed with HBSS twice, and incubated with $5 \mathrm{~m} l$ of $0.25 \%$ trypsin at $37^{\circ} \mathrm{C}$ for $10 \mathrm{~min}$. After washing with HBSS, the cerebella were dissociated with a Pasteur pipette in DNase solution $(40 \mathrm{U} / \mathrm{m} l)$, and centrifuged at $400 \times \mathrm{g}$ for $3 \mathrm{~min}$. The cell pellets were suspended in DMEM/F-12 (Invitrogen Ltd., U.S.A.) with $10 \%$ FCS (finally $1-2 \times 10^{6} \mathrm{cell} / \mathrm{ml}$ ), and seeded onto a $10 \mu \mathrm{g} / \mathrm{m} l$ poly-L-ornithine (PLO)-coated culture dish (35 $\mathrm{mm}$ in diameter). After 20 min incubation at $37^{\circ} \mathrm{C}$ in a $5 \% \mathrm{CO}_{2}$ atmosphere with $95 \%$ humidity, nonattached cells were collected, suspended at 1,5 and $10 \times 10^{5}$ cell/300 $\mu l$ of DMEM/F-12, and seeded onto $500 \mu \mathrm{g} / \mathrm{m} l$ 


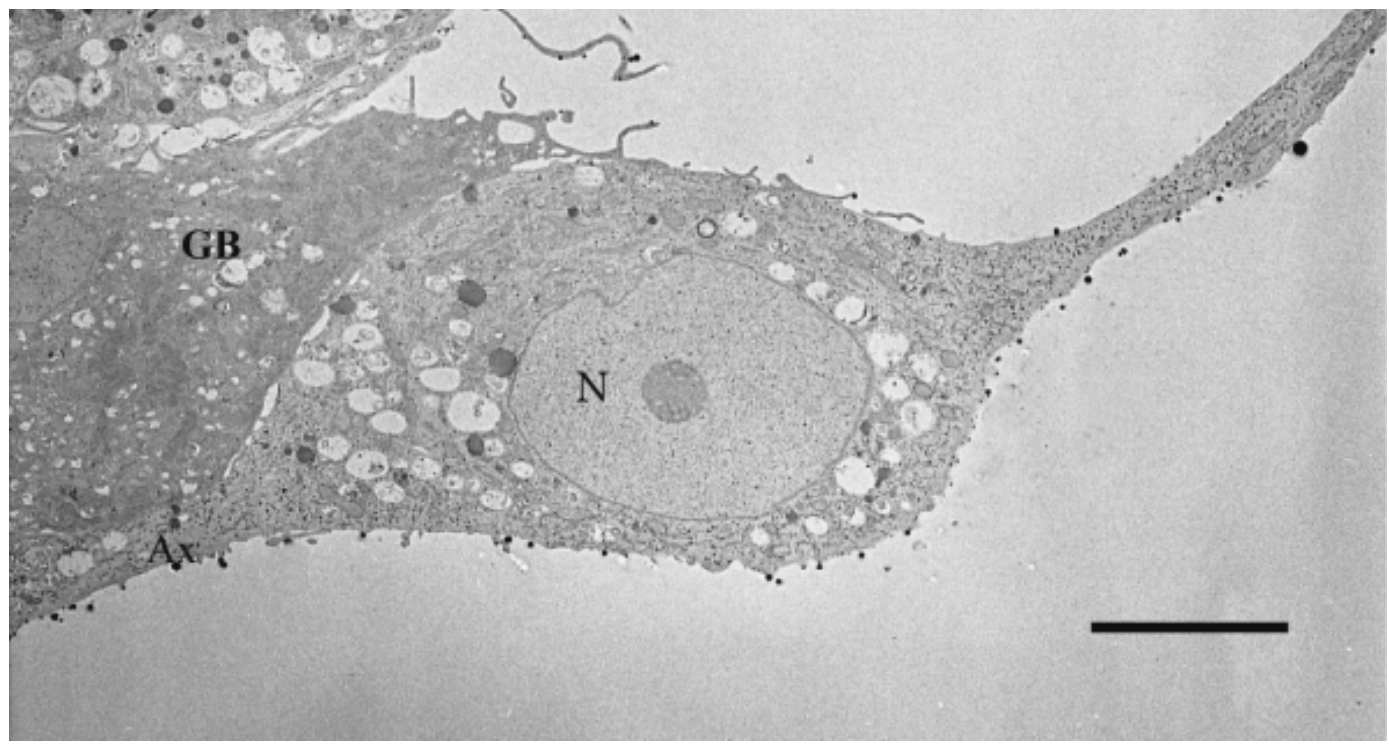

Fig. 3. Electron micrograph of neuron in co-culture for 3 days. Neuron possesses a large round nucleus (N) with prominent nucleolus. The cytoplasm of neuron is low electron dense than that of GB cell (GB). Ax: axon. Bar: $10 \mu \mathrm{m}$.

PLO-coated culture dishes with $13.5 \mathrm{~mm}$ diameter coverslips. After $3 \mathrm{hr}$ incubation at $37^{\circ} \mathrm{C}$ in a $5 \% \mathrm{CO}_{2}$ atmosphere with $95 \%$ humidity, $3 \mathrm{~m} l$ of DMEM/F-12 with $1 \% \mathrm{FCS}$ and supplements $(20 \mathrm{nM}$ progesterone, $10 \mu \mathrm{g} / \mathrm{m} l$ bovine insulin, $100 \mu \mathrm{g} / \mathrm{m} l$ transferrin, $100 \mu \mathrm{M}$ putrescine, $30 \mathrm{nM}$ sodium selenite, and $0.5 \mathrm{ng} / \mathrm{m} l$ tri-iodothyronine) was added to each dish. The supplements were purchased from Sigma Chemical Co. (U.S.A.). After $18 \mathrm{hr}$, half of the medium was replaced with fresh DMEM/F-12, supplements and cytosine arabinoside $(1.4 \mu \mathrm{g} / \mathrm{m} l)$.

Co-culture: The DiI labeled GB cells were washed and resuspended at $5 \times 10^{5}$ cells $/ 3 \mathrm{~m} l$ of DMEM/F-12 with the supplements. The cell suspensions were added to neuron cultures of 6 days after plating, and incubated for 3 days.

Morphological assays: For light microscopical observations, all cultures were fixed with $10 \%$ formalin for $10 \mathrm{~min}$, and rinsed in $0.01 \mathrm{M}$ phosphate-buffered saline $(\mathrm{pH} 7.4)$, and observed under phase contrast microscope (Olympus, Japan). The neuron cultures were incubated with primary antisera against tubulin (dilution $200 \times$; Neo Markers, U.S.A.) for $18 \mathrm{hr}$ at $4^{\circ} \mathrm{C}$, following FITC conjugated secondary antisera (dilution $100 \times$; Seikagaku Kogyo Co., Ltd., Japan) for $1 \mathrm{hr}$ at room temperature. The FITC and DiI fluorescents were detected under fluorescent microscope (Olympus, Japan) at 488 and $546 \mathrm{~nm}$ of the exciting wavelength, respectively.

For electron microscopical observations, the co-cultures, after observation under fluorescent microscopy, were fixed with a mixture of $2 \%$ paraformaldehyde and $2.5 \%$ glutaraldehyde in $0.1 \mathrm{M}$ phosphate buffer for $1 \mathrm{hr}$ followed by postfixation with $1 \% \mathrm{OsO}_{4}$ in the same buffer for $1 \mathrm{hr}$ at $4{ }^{\circ} \mathrm{C}$. After dehydration with graded ethanol, the cell sheets were covered with the gelatin capsules filled by epoxy resin (Epok-812). Thick sections were stained with toluidine blue. Ultrathin sections were stained with uranyl acetate and lead citrate and observed under transmission electron microscope (JEOL 1210, Japan).

\section{RESULTS}

The cultured GB cells were attached to the dish 1 day after seeding. The cells were flat with processes and the nuclei were oval in shape. After DiI labeling, the cytoplasmic and nuclear membranes were detectable as red fluorescent. The labeling ratios of the GB cells were changed by the culture periods; the ratio (positive cells/200 cells) was $73.3 \pm 7.4 \%$ at 3 days, $54.5 \pm 11.1 \%$ at 6 days and $22.8 \pm$ $4.6 \%$ at 9 days after incubation. In the following co-culture analysis, we used the GB cells labeled with DiI at 3 days after incubation.

Growing of neurons in dish depended on culture conditions especially on cell density at seeding. Cells at low density $\left(1 \times 10^{5}\right.$ and $5 \times 10^{5}$ cells $\left./ \mathrm{m} l\right)$ were not attached or dead in the early period of incubation. Neurons at seeding density $1 \times 10^{6}$ were successfully attached to the PLO-coated culture dish after 3 to 6 days of incubation (Fig. 1a). Most of the cells were tubulin-positive, and their processes exhibited a meshwork structure (Fig. 1b).

In co-cultures of GB cells and cerebellar neurons, DiIpositive cells formed small clusters, and some single cells were beside the large neurons (Fig. 2). The single cells then attached to the neuronal body and the base of the thick process (Fig. 2). The ratio of the clustered cells and single cells was about 7 to 1 under fluorescent microscope. Under electron microscope, the neurons were distinguished by large round nuclei with a prominent nucleolus, and by microtubules in the axon and axon hillock (Fig. 3). GB cells were easily detected by their nuclei with irregular margins, and 

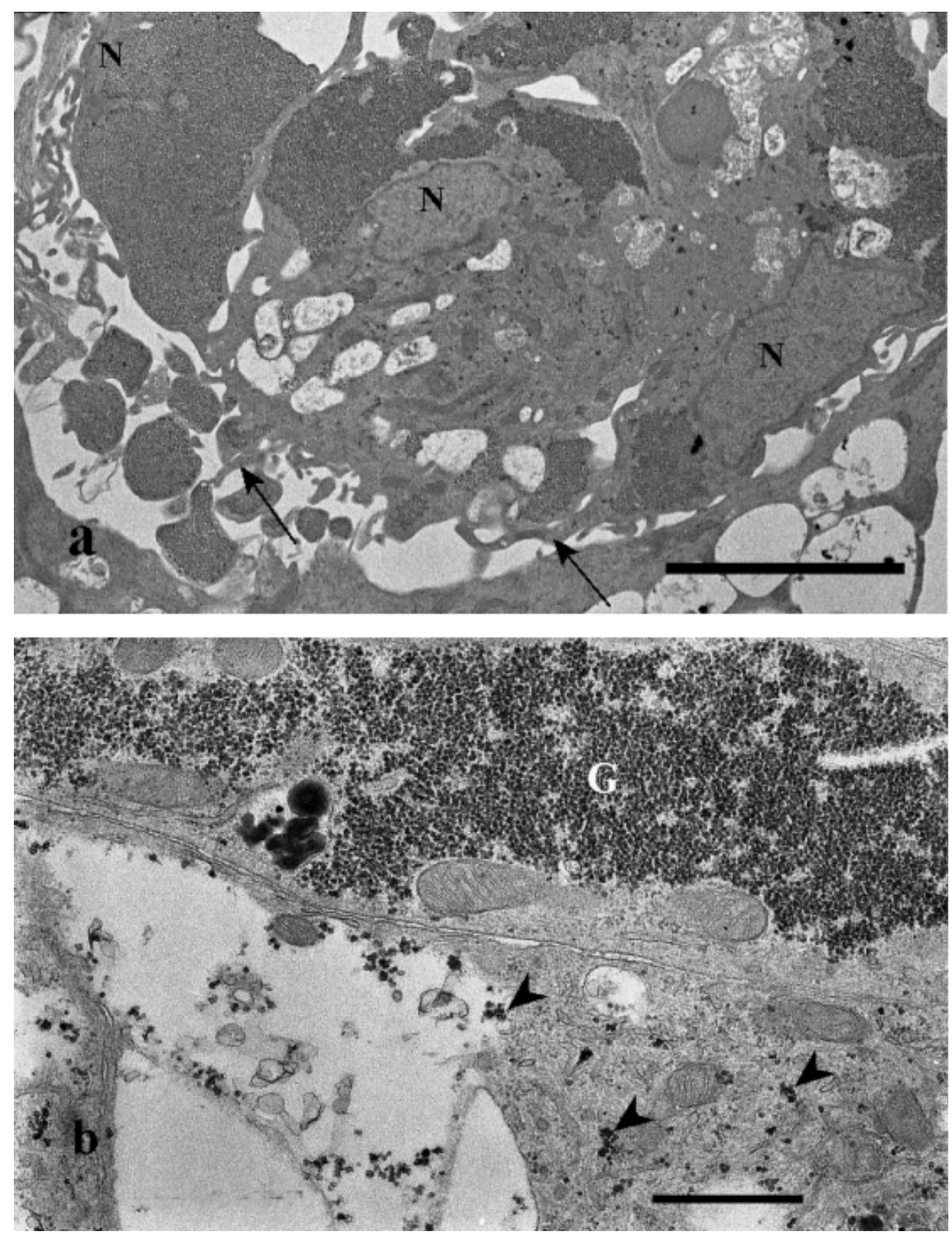

Fig. 4. Electron micrographs of GB cells in co-culture for 3 days. (a) GB cells possess irregular shape nucleus (N) and electron dense cytoplasm with a short thin processes (arrows). (b) The cytoplasm of clustered GB cells contains numerous glycogen granules as dense deposits $(\mathrm{G})$ or coarse rosettes (arrowheads). Fibrous element is little. Bars: $10 \mu \mathrm{m}$ in A and $1 \mu \mathrm{m}$ in B.

electron-dense cytoplasm, in which glycogen particles and a few vacuoles were observed. GB cells in the small clusters possessed large glycogen deposits and a few intermediate filaments in the cytoplasm (Fig. 4). The single GB cells, beside a neuronal body, extended the processes surrounding the axon. The cytoplasm of the processes was rich with intermediate filaments and a few scattered glycogen granules (Fig. 5). In the axon surrounded by GB processes, small electron-lucent vesicles 40 to $50 \mathrm{~nm}$ in diameter were found as well as microtubules (Fig. 5). Membranous changes like pre- and post-synaptic membranes were not detected at either the axon or the GB cell membrane.

\section{DISCUSSION}

Among the various hypotheses about the function of GB 

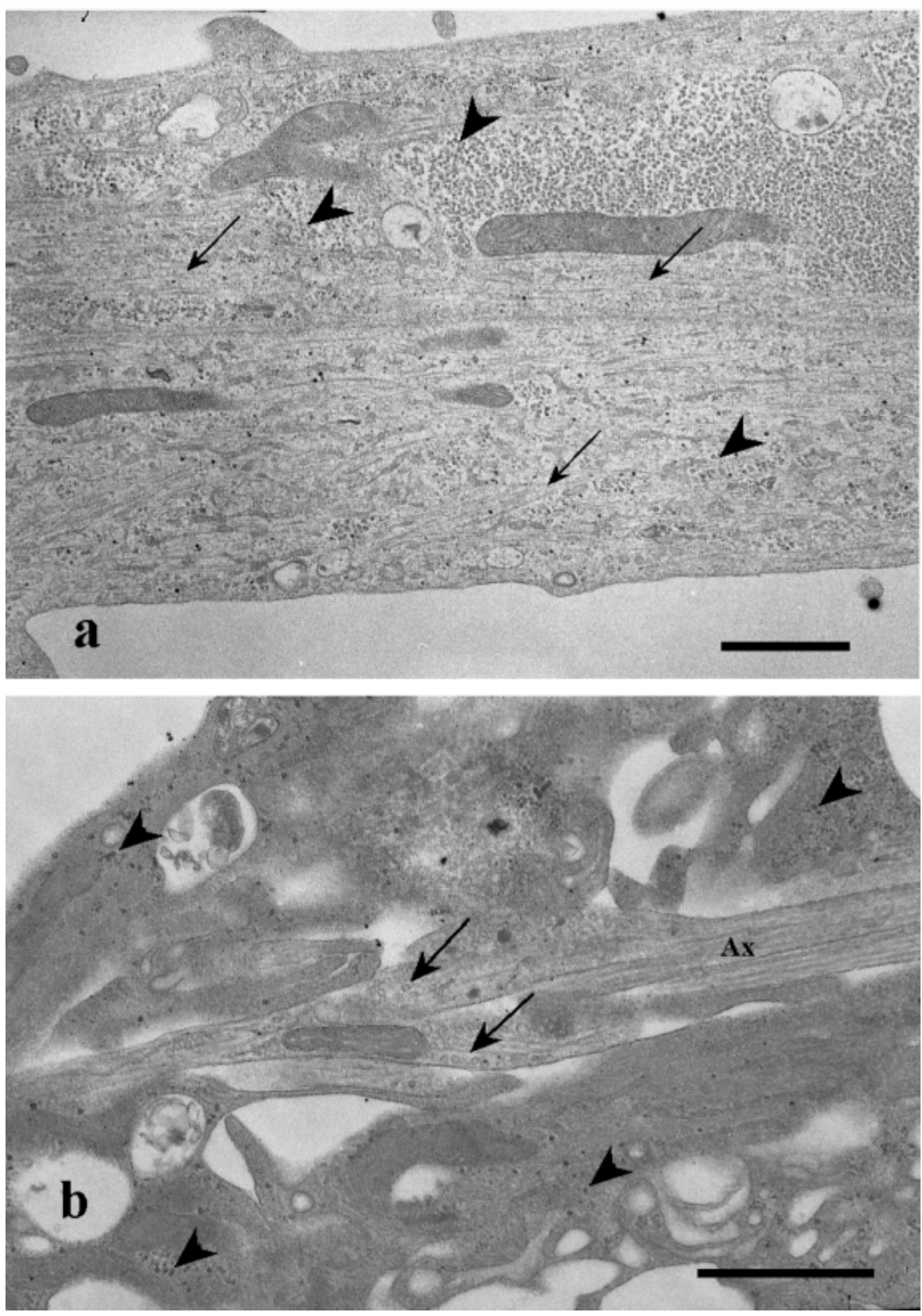

Fig. 5. Electron micrographs of GB cells in co-culture for 3 days. (a) The processes of single GB cells include intermediate filaments (arrows) and glycogen beta particles throughout the cytoplasm (arrowheads). (b) The processes of GB cells surround axon (Ax). Cytoplasm contains scattered glycogen granules (arrowheads). In the axon, small round vesicles (arrows) are visible. Bars: $1 \mu \mathrm{m}$. 
cells, most classical and the major view suggest it to be an energy reservoir in avian CNS because of the high glycogen content. One author proposed the function of GB as a secretory cell from ultrastructural observations [15]. Also, Benzo and colleagues have proposed a hypothesis that GB cells are metabolically linked to lipid synthesis and myelin formation in the avian embryo [2, 3].

It is well known that astrocytes maintain the synapse functions in mature animals $[1,30]$. Especially in cerebellum, astrocytes regulate the number of Purkinje cell axosomatic and axospinous synapses and promote the structural and functional maturation of Purkinje cells [22]. Recently, Ullian et al. [28] reported that astrocytes promote functional synapses in the spinal cord and maintain the synapses in vitro. In the present in vitro study, some of the GB cells attached to the cerebellar neuron and processes surrounded the axon including synaptic vesicles; GB cells possessed rich intermediate filaments and a small glycogen store unlike typical GB cells. Since the neurons influence the differentiation, morphology and GFAP gene expression of the astrocytes [10, 12], it is suggested that a part of GB cells show astrocytic features by contacting with neurons. These GB cells may function as synapse promoters.

Most investigators have recognized GB in the form of uniform cell clusters. In the present study, we detected 2 types of GB cells in co-culture with neurons. One type was the conventional GB cell, which formed cell clusters and contained a large volume of glycogen in the cytoplasm. Another type independently contacted neurons and extended the process along the soma and axonal processes. Except for the induction of astrocytic GB cells from one cell lineage, the morphological differences of GB cells might be explained under the present conditions as due to: 1) contamination with cerebellar or spinal cord astrocytes, and 2) heterogeneity of GB cells.

Addition of cytosine arabinoside, a selective DNA synthesis inhibitor, eliminates proliferative glial cells [26]. In the present cerebellar cell cultures treated with cytosine arabinoside, most of the astrocytes were eliminated. The cerebellar astrocytes persisting in co-cultures were easily distinguished from GB cells by their irregular-shaped nucleus and many vacuoles in the cytoplasm (data not shown). The GB primordia of chicken are completely fused after 11 days of incubation [27] and are macroscopically detectable after 15 days of incubation $[6,19]$. Under dissection microscopy, the boundary of GB and spinal cord matter was clearly distinguished at 15 days of incubation, and so it is unlikely that the astrocytic GB cells are from cerebellar or spinal cord astrocytes.

Developmentally, the GB consisted of two parts, the roof plate and the floor plate of the neural canal [27, 29]. Morphologically, no reports describe the differences between GB cells from the roof and floor plates. The present morphological differences of GB cells might reflect their roof and floor plate origin.

In mammals, the choroid plexus ependymal cells have been suggested to have the potential to change into other types of glial cells after grafting [17]. The morphological features of the stem cells remain controversial. The choroid plexus and ventricular ependymal cells do not express GFAP at any normal developmental stage in humans [21] or rodents $[5,25]$, while the human adult stem cells show an astrocytic morphology and express GFAP [20,32]. In the early stage of chicken development, the GB appears as a paired primordia separated by the ependymal septum, which exist until 11 days of incubation [27]. The appearance of astrocytic GB cells in co-culture suggests that GB may include a neural stem cell.

\section{REFERENCES}

1. Barres, B.A. 1991. New roles for glia. J. Neurosci. 11: 36853694.

2. Benzo, C.A. and De Gennaro, L.D. 1983. An hypothesis of function for the avian glycogen body: a novel role for glycogen in the central nervous system. Med. Hypothes 10: 69-76.

3. Benzo, C.A., De Gennaro, L.D. and Stearns, S.B. 1975. Glycogen metabolism in the developing chick glycogen body: functional significance of the direct oxidative pathway. J. Exp. Zool. 193: 161-166.

4. Bergles, D.E. and Jahr, C.E. Jahr, 1998. Glial contribution to glutamate uptake at Schaffer collateral-commissural synapses in the hippocampus. J. Neurosci. 18: 7709-7716.

5. Bruni, J.F. 1998. Ependymal development, proliferation, and functions: a review. Microsc. Res. Tech. 41: 2-13.

6. De Gennaro, L.D. 1959. Differentiation of the glycogen body of the chick embryo under normal and experimental conditions. Growth 23: 235-249.

7. De Gennaro, L.D. 1993. Origin of the avian glycogen body. II. Observations in support of a glial nature in the chick embryo. Growth Dev. Aging 57: 275-281.

8. De Gennaro, L.D. and Benzo, C.A. 1991. Development of the glycogen body of the Japanese quail, Coturnix japonica.. II. Observations of electron microscopy. J. Morphol. 207: 191199.

9. Furuya, S., Makino, A. and Hirabayashi, Y. 1998. An improved method for culturing cerebellar Purkinje cells with differentiated dendrites under a mixed monolayer setting. Brain Res. Protocols 3: 192-198.

10. Gomes, F.C.A., Garci-Abreu, J., Galou, M., Paulin, D. and Neto, V.M. 1999. Neurons induce GFAP promoter of cultured astrocytes from transgenic mice. Glia 26: 97-108.

11. Graber, G., Lefeille, A. and Netke, S.P. 1972. Effect of fasting on glycogen body stability in the mature chicken. Poult. Sci. 51: 704-705.

12. Hatten, M.E. 1985. Neuronal regulation of astroglial morphology and proliferation in vitro. J. Cell Biol. 100: 384-396.

13. Haydon, P.G. 2001. Glia: listening and talking to the synapse. Nat. Rev. Neurosci. 2: 185-193.

14. Hazelwood, B.S. and NcNary, W.F. 1962. Possible hypophysial control over glycogenesis in the avian glycogen body. Endocrinology 31: 334-336.

15. Inigo, A., Fernandez-Soriano J. and Fernandez-Ruiz, B. 1985. Is the avian glycogen body a secretory organ? J. Hirnforsch. 26: 651-657.

16. Jankaskova, B., Satstny, F., Lisy, V., Pearce, B. and Murphy, S.1988. Effect of inhibitors of gamma-glutamyl transpeptidase on the uptake of glutamate and asparate into cultured astroglial cells from the glycogen body and cerebral hemispheres of the 
embryonic chick. Physiol. Bohemoslovaca 37: 131-134.

17. Kitada, M., Chakrabortty, S., Matsumoto, N., Taketomi, M. and Ide, C. 2001. Differentiation of choroid plexus ependymal cells into astrocytes after grafting into the pre-lesioned spinal cord in mice. Glia 36: 364-374.

18. Lee, K., Makino, S., Imagawa, T., Kim, M. and Uehara, M. 2001. Effects of adrenergic agonists on glycogenolysis in primary cultures of glycogen body cells and telencephalon astrocytes of the chick. Poult. Sci. 80: 1736-1742.

19. Matulionis, D.H. 1972. Analysis of the developing avian glycogen body. J. Morphol. 137: 463-482.

20. Sanai, N., Tramontin, A.D., Quinones-Hinojosa, A., Barbaro, N.M., Gupta, N., Kunwar, S., Lawton, M.T., WcDermott, M.W., Parsa, A.T., Verdugo, J.M-G., Berger, M.S. and Alvarez-Vuylla, A. 2004. Unique astrocyte ribbon in adult human brain contains neural stem cells but lacks chain migration. Nature (Lond.) 427: 740-744.

21. Sarnat, H.B. 1998. Histochemistry and immunocytochemistry of the developing ependyma and choroid plexus. Microsc. Res. Tech. 41: 14-28.

22. Seil, F.J. 2001. Interactions between cerebellar Purkinje cells and their associated astrocytes. Histol. Histopathol. 16: 955968.

23. Shulman, R.G., Hyder, F. and Rothman, D.L. 2001. Cerebral energetics and the glycogen shunt: neurochemical basis of functional imaging. Proc. Natl. Acad. Sci. U.S.A. 98: 64176422 .

24. Snedecor, J.G., King, D.B. and Henrikson, R.C. 1963. Studies on the chick glycogen body: effects of hormones and normal glycogen turnover. Gen. Comp. Endocrinol. 3: 176-183.

25. Sommer, I., Lagenaur, C. and Schachner, M. 1981. Recognition of Bergmann glial and ependymal cells in the mouse nervous system by monoclonal antibody. J. Cell Biol. 90: 448458.

26. Tabata, T., Sawada, S., Araki, K., Bono, Y., Furuya, S. and Kano, M. 2000. A reliable method for culture of dissociated mouse cerebellar cells enriched for Purkinje neuron. J. Neurosci. Method 104: 45-53.

27. Uehara, M. and Ueshima, T. 1982. Development of the glycogen body through the whole length of the chick spinal cord. Anat. Rec. 202: 511-519.

28. Ullian, E.M., Harris, B.T., Wu, A., Chan, J.R. and Barres, B.A 2004. Schwann cells and astrocytes induce synapse formation by spinal motor neurons in culture. Mol. Cell. Neurosci. 25: 241-251.

29. Vukovic, S. and Lucic, H. 2005. Development of the glycogen body in turkey (Meleagris gallopavo) embyo. Veterinarski Archiv. 75: 101-110.

30. Walz, W. 1989. Role of glial cells in the regulation of the brain ion microenvironment. Prog. Neurobiol. 33: 309-333.

31. Watterson, R.L. 1949. Development of the glycogen body of the chick spinal cord. J. Morphol. 85: 337-390.

32. Watts, C., McConkey, H., Anderson, L. and Caldwell, M. 2005. Anatomical perspectives on adult neural stem cells. $J$. Anat. 207: 197-208. 